\title{
Efeitos do Estresse Térmico Sobre a Produção, Composição Química do Leite e Respostas Termorreguladoras de Cabras da Raça Alpina
}

\author{
Lúcia Helena de Albuquerque Brasil ${ }^{1}$, Francisco Stefano Wechesler², Flávio Baccari Júnior ${ }^{3}$, \\ Heraldo Cesar Gonçalves ${ }^{2}$, Ismael Antônio Bonassi ${ }^{4}$
}

\begin{abstract}
RESUMO - Seis cabras da raça Alpina, com produção média de leite de 2,5 kg/dia, foram distribuídas aleatoriamente em dois grupos de três e submetidas à termoneutralidade ou estresse térmico por 56 dias em câmara climática. Usou-se um delineamento estatístico "crossover". A temperatura média do ar diurna, incluindo radiação solar simulada, foi de $33,84^{\circ} \mathrm{C}$. Os animais estressados aumentaram a freqüência respiratória, o volume-minuto respiratório, a termólise-evaporativa respiratória, temperatura retal e a taxa de sudorese, enquanto o volume corrente respiratório e o volume globular diminuíram. Houve também perda de peso, redução da ingestão de alimentos e duplicação do consumo de água. A produção de leite e a porcentagem de gordura, proteína, lactose e sólidos totais diminuíram. Os teores de cloretos, cálcio e fósforo não sofreram alteração. Concluiu-se que, para manter a homeotermia, as cabras mobilizaram o sistema respiratório e sudoríparo para perder calor. A alta temperatura ambiente efetiva reduziu a produção e os teores de alguns componentes do leite.
\end{abstract}

Palavras-chave: cabras, composição química, estresse térmico, produção de leite

\section{Thermal Stress Effects on Milk Yield and Chemical Composition and Thermoregulatory Responses of Lactating Alpines Goats}

\begin{abstract}
Six Alpine goats with an average milk yield of $2.5 \mathrm{~kg}$ /day were randomly assigned to two groups of three and allotted to thermoneutral or heat stress conditions, for 56 days in climate chamber room. A crossover experimental design was used. The goats under heat stress were exposed to a diurnal average air temperature plus simulated solar radiation of $33.84^{\circ} \mathrm{C}$. The heat-stressed goats showed elevated respiratory frequency, respiratory minute volume, respiratory evaporation, rectal temperature and sweating rate, while the tidal volume and packed cell volume decreased. Further weight loss, decreased feed intake, and their water consumption doubled. The milk yield, the percentage of fat, protein, lactose and total solid contents decreased. The contents of chloride, calcium and phosphorus did not change. The goats mobilized the respiratory and sweating systems to lose heat to maintain homeothermy. The association between high air temperature and simulated solar radiation reduced the milk yield and the content of some milk components.
\end{abstract}

Key Words: goats, chemical composition, thermal stress, milk production

\section{Introdução}

Do ponto de vista bioclimático, apesar de os caprinos serem considerados animais rústicos, a associação entre elevadas temperaturas e altas umidades do ar e radiação pode acarretar alterações comportamentais e fisiológicas, como aumento da temperatura da pele, elevação da temperatura retal, aumento da freqüência respiratória, diminuição da ingestão de alimentos e redução do nível de produção (LU, 1989).

Embora a cabra leiteira seja importante fonte produtora de proteínas e minerais para o consumo humano, tem havido limitado esforço para descrever os efeitos do estresse térmico sobre sua produtividade.
BIANCA e KUNZ (1978) mostraram que cabras leiteiras, em condições estressantes $\left(40,0^{\circ} \mathrm{C}\right.$ e $30 \%$ UR) tiveram a temperatura retal e freqüência respiratória elevadas. Em condições naturais, caprinos da raça Crioula, expostos à radiação solar direta, apresentaram aumento da temperatura retal (SERGENT et al. 1985). Em caprinos jovens, KAUSHISH et al. (1987) observaram aumentos de temperatura retal e freqüência respiratória em duas raças indianas após duas horas de exposição ao sol. O estudo de algumas reações fisiológicas de cabras adultas Saanen-Nativas seca em câmara climática, realizado por GAYÃO et al. (1991), mostrou que, pela manhã (9 horas), a freqüência respiratória e a temperatura da pele foram mais elevadas no grupo estressado que no grupo

\footnotetext{
${ }^{1}$ Prof. Adjunto, Dep. Zootecnia, UFRPE - Recife - PE. E.mail: brasilnelore@npde.ufrpe.br

2 Prof. Assistente doutor, Dep. Produção e exploração Animal - Fazenda Lageado - FMVZ - UNESP, CEP 18618-000, Campus de Botucatu - SP

${ }^{3}$ Prof. Titular, Prof. pesquisador, Dep. Clínica Veterinária, CCA, UEL - Londrina - PR.

4 Prof. Titular, Dep. Tecnologia de Alimentos, Fazenda Lageado - FMVZ - UNESP, CEP18618-000, Campus de Botucatu - SP.
} 
controle, não havendo diferença entre grupos quanto à temperatura retal. À tarde (15 horas), a freqüência respiratória e a temperatura retal foram significativamente mais elevadas no grupo estressado que no grupo controle. Respostas termorreguladoras de cabras Alpinas não-lactantes, em câmara climática, mostraram maiores freqüência respiratória, volume-respiratório minuto, termólise-evaporativa respiratória e temperatura retal nos animais sob estresse que os animais em condições termoneutras. DAS (1995) mostrou variação na capacidade de perda de suor pelos animais, de acordo com a região do corpo, relatando taxa mais intensa na região da paleta em caprinos da raça Sirohi. Para cabras Saanen em lactação e Alpinas nãolactantes, respectivamente, BACCARI et al. (1996) e BACCARI et al. (1997) relataram taxa de sudorese mais elevada para os animais sob estresse térmico.

Fatores como ingestão de alimento, perda de eletrólitos e água durante o estresse térmico podem influenciar a osmolaridade e volume sangüíneo de diversos ruminantes (ERIKSSON et al., 1994; OLSSON et al., 1995). Entretanto, BACCARI et al. (1996b), trabalhando com cabras Saanen na $10^{\mathrm{a}}$ semana de lactação, e BACCARI et al. (1997), com cabras Alpinas não-lactantes, não mostraram diferença significativa entre o grupo tratamento e o grupo controle, quanto ao volume globular. Redução de $36,6 \%$ na produção leiteira de um rebanho de cabras Saanen importado e introduzido numa região tropical foi verificado por ESMAIL (1986). Do mesmo modo, BROWN et al. (1988) observaram que a produção diária de leite de cabras Alpinas diminuiu, quando a temperatura ambiente se elevou de 20 para $34^{\circ} \mathrm{C}$. Em contraste, BACCARI et al. (1996a) mostraram que cabras Saanen submetidas à temperatura de $32,5^{\circ} \mathrm{C}$ em câmara bioclimática, reduziram o consumo de matéria seca e aumentaram o consumo diário de água, mas a produção de leite foi semelhante à de suas companheiras em condições de conforto térmico. Resultados de estudos com caprinos das raças Saanen, Anglo-Nubiana e Alpina, em clima tropical, indicaram que, além da baixa produção, alguns componentes do leite, como gordura e sólidos totais, apresentaram valores menores que aqueles das mesmas raças, criadas em clima temperado, devido à dieta inadequada $\mathrm{e}$ temperaturas elevadas do ar (JUARÉZ, 1986).

SHIPE (1969) e DEVENDRA (1981) relataram que a composição do leite caprino pode variar de acordo com o intervalo de ordenha. DIAS et al. (1995) mostraram que o leite da tarde apresentou maior concentração nos teores de cloretos e cinzas que o da manhã, enquanto o teor de cálcio foi maior pela manhã. TANEZINI et al. (1995) não verificaram diferenças significativas entre manhã e tarde, quanto ao teor de lactose.

\section{Material e Métodos}

O trabalho foi realizado na câmara bioclimática da Fazenda Experimental Lageado, Campus de Botucatu - UNESP, no período de março a maio de 1996.

Seis cabras da raça Pardas Alpina, na $5^{\mathrm{a}}$ semana de lactação, foram distribuídas ao acaso em dois grupos de três, com idade e peso iniciais médios de 20,5 meses e $39 \mathrm{~kg}$, respectivamente, e produção média diária de leite de $2,5 \mathrm{~kg} / \mathrm{cabra}$. Cada grupo ficou alojado em uma sala. Na sala 1, os animais permaneceram em condições de termoneutralidade e, na sala 2 , sofreram estresse das 8 às $17 \mathrm{~h}$, com radiação solar direta simulada por duas lâmpadas infravermelhas de $250 \mathrm{~W}$ sobre cada animal, das 10 às $15 \mathrm{~h}$. Todos os animais foram mantidos em baias individuais com piso de concreto $(0,8 \mathrm{~m} \times 1,3 \mathrm{~m})$ sobre estrado ripado com acesso a cocho e bebedouro.

Durante todo o período experimental, forneceu-se $1,0 \mathrm{~kg} / \mathrm{animal} / \mathrm{dia}$ de mistura concentrada, que continha $23,81 \%$ de proteína bruta e 7,26\% de fibra bruta e $79 \%$ de NDT (estimados) na matéria seca. Feno de Cynodon dactylon (L.) Pers. cv. "Coastcross" com $3,96 \%$ de proteína bruta, $34,08 \%$ de fibra bruta e $44 \%$ de NDT (estimados) na matéria seca e água foi consumido à vontade. $\mathrm{O}$ consumo de alimento foi determinado nos períodos diurno e noturno, das 8 às $17 \mathrm{~h}$ e das 17 às $8 \mathrm{~h}$, pesando-se a sobra do alimento, individualmente, no final de cada período, e subtraindo-se do total oferecido nesse mesmo período. $\mathrm{O}$ consumo de água foi determinado nos mesmos períodos, mediante leitura dos hidrômetros dos bebedouros automáticos e consumo de água no balde fornecido como complementação durante a noite. Os animais foram pesados semanalmente, todas as segundas-feiras, após a ordenha e antes da primeira alimentação.

A temperatura e a umidade do ar foram registradas continuamente mediante dois termoigrógrafos, colocados um em cada sala da câmara. Foi anotada diariamente, de hora em hora, a temperatura radiante (de forma indireta), por intermédio de dois termômetros de Botsball e dois termômetros de globo negro e (BOTSFORD, 1971; HOWARD ENGINEERING COMPANY, 1981), um em cada sala da câmara. Foi calculado também o "Índice de Temperatura e Umidade THI”, de acordo com KELLY e BOND (1971). 
1634 Rev. bras. zootec.

A temperatura do ar, a umidade relativa do ar e os índices bioclimáticos, a temperatura do globo negro (BGT), o índice de temperatura e umidade (THI) e a temperatura do Bostsball (BT), calculados para caracterizar o ambiente térmico das salas 1 e 2 da Câmara Bioclimática, durante o período experimental, constam na Tabela 1 .

A frequiência respiratória foi contada pela observação dos movimentos laterais do flanco. O volumecorrente respiratório foi medido por meio de máscara facial e espirômetro. O volume-minuto respiratório foi obtido por meio da multiplicação do volumecorrente respiratório pela frequiência respiratória. A temperatura retal foi tomada mediante termômetro clínico digital humano. A termólise-evaporativa respiratória foi calculada de acordo com McDOWELL (1975). A taxa de sudorese foi avaliada pelo método de BERMAN (1957), modificado por SCHLEGER e TURNER (1965). Para a análise do volume globular, coletaram-se amostras de sangue mediante punção da veia jugular, usando-se a técnica do microhematócrito. Frequiência respiratória, volume-corrente respiratório, volume-minuto respiratório termólise-evaporativa respiratória, temperatura retal, taxa de sudorese e volume globular foram medidos duas vezes por semana, entre 14 e 15 h. Freqüência respiratória, volume-corrente respiratório e temperatura retal foram medidos também às $9 \mathrm{~h}$.

O controle individual da produção de leite foi feito mediante pesagens após a ordenha, efetuadas sempre pela manhã $(8 \mathrm{~h})$ e à tarde $(16 \mathrm{~h})$ e registradas em fichas apropriadas. Antes da ordenha, foram obedecidos os critérios higiênicos normais. Fezes e urina foram removidas mediante lavagem diária das instalações.

$\mathrm{Na}$ segunda semana de cada intervalo experimental, amostras de leite individuais $(500 \mathrm{~mL}$ pela manhã e $300 \mathrm{~mL}$ à tarde) foram coletadas diariamente (6 cabras x 7 dias x 2 períodos x 4 intervalos, perfazendo 336 amostras). Para conservação da amostra, adicionou-se solução a $40 \%$ de formaldeído na proporção de $1 \mathrm{~mL} /$ litro da amostra, conforme o INSTITUTO ADOLFO LUTZ (1985), e armazenou-se sob refrigeração a $4{ }^{\circ} \mathrm{C}$ para posterior análise. Ao final do quarto intervalo experimental, as 28 amostras de cada cabra por período foram misturadas, formando-se assim amostras compostas, nas quais foram efetuadas as seguintes determinações: acidez titulável e matéria graxa, segundo o INSTITUTO ADOLFO LUTZ (1985); sólidos totais, cinzas, proteína bruta, lactose e cloretos, segundo a ASSOCIATION OF OFFICIAL ANALYTICAL CHEMISTS - AOAC
(1975); e cálcio e fósforo, por espectrometria de chama (MALAVOLTA et al.1989).

Os animais passaram por um período de adaptação de 28 dias em condições de termoneutralidade em câmara bioclimática. A seguir, foram distribuídos aleatoriamente em dois grupos de três cabras e submetidos a dois tratamentos, termoneutralidade (TN) e estresse térmico (ST) em quatro intervalos de 14 dias cada.

Para efeito de análise estatística, foram considerados os dados coletados na segunda semana de cada intervalo. $\mathrm{O}$ experimento foi analisado como um delineamento estatístico "crossover," no qual cada cabra observada em um período constituiu uma parcela principal e cada período do dia (manhã ou tarde), uma subparcela. A análise estatística foi efetuada por meio do programa GLM (STATISTCAL ANALYSIS SYSTEM, 1985) e as inferênciass obtidas basearam-se no nível de 5\% de significância.

\section{Resultados e Discussão}

Durante o estresse térmico, no período das 8 às $17 \mathrm{~h}$ (Tabela 1), a temperatura do ar esteve cerca de $4^{\circ} \mathrm{C}$ acima da temperatura crítica superior para cabras Alpinas americanas, referida por LU (1989), com o THI de 86,47, o qual representa uma condição de emergência para os animais de produção de modo geral (HAHN, 1985). A temperatura do globo negro e a temperatura do bostsball, no mesmo período, foram 36,08 e $32,18^{\circ} \mathrm{C}$, respectivamente.

$\mathrm{Na}$ Tabela 2, verifica-se que a freqüência respiratória (FR), o volume corrente respiratório (VC), volume-minuto respiratório (VM), a termóliseevaporativa respiratória (TE) e a temperatura retal (TR) apresentaram médias mais elevadas à tarde que pela manhã. Efeito oposto foi verificado para o VC. Observa-se que a diferença entre manhã e tarde foi sempre maior nos animais estressados. Temperaturas ambientes efetivas mais altas à tarde (especialmente no tratamento ST), associadas à elevação da temperatura corpórea provocada pelo ciclo nictemeral dos animais, foram os fatores responsáveis por estes efeitos. Observa-se ainda que as médias de FR, VM, TE e TR foram significativamente mais elevadas $(\mathrm{P}<0,05)$ nos animais estressados. Efeito contrário $(\mathrm{P}<0,05)$ foi observado para o VC.

Na Tabela 3, apresentam-se as médias ajustadas da taxa de sudorese (TS) e do volume globular (VG), avaliadas à tarde $(15 \mathrm{~h})$. Os animais estressados apresentaram elevação significativa da TS e redução do VG. 
BRASIL et al.

Tabela 1 - Médiasterro-padrão das variáveis climáticas durante o período experimental (56 dias) Table 1 - Means \pm standard error of climatic variables during the experimental period (56 days)

\begin{tabular}{|c|c|c|c|c|}
\hline \multirow[t]{3}{*}{$\begin{array}{l}\text { Variável } \\
\text { Variable }\end{array}$} & \multirow{2}{*}{\multicolumn{2}{|c|}{$\begin{array}{c}\text { Termoneutralidade }(\mathrm{TN}) \\
\text { Thermoneutral }(T N) \\
\text { Período } \\
\text { Period } \\
\end{array}$}} & \multirow{2}{*}{\multicolumn{2}{|c|}{$\begin{array}{c}\text { Estresse térmico }(\mathrm{ST}) \\
\text { Thermal stress }(S T) \\
\text { Período } \\
\text { Period } \\
\end{array}$}} \\
\hline & & & & \\
\hline & $8-17 \mathrm{~h}$ & $17-8 \mathrm{~h}$ & $8-17 \mathrm{~h}$ & $17-8 \mathrm{~h}$ \\
\hline $\begin{array}{l}\text { Temperatura do ar }\left({ }^{\circ} \mathrm{C}\right) \\
\text { Air temperature }\left({ }^{\circ} \mathrm{C}\right)\end{array}$ & $22,82 \pm 0,31$ & $22,25 \pm 0,31$ & $33,84 \pm 0,23$ & $27,19 \pm 0,24$ \\
\hline $\begin{array}{l}\text { Umidade relativa (UR), } \% \\
\text { Relative humidity }(R U)\end{array}$ & $76,67 \pm 0,91$ & $77,73 \pm 0,70$ & $66,11 \pm 0,70$ & $75,68 \pm 0,46$ \\
\hline $\begin{array}{l}\text { Índice de temperatura e umidade (ITU) } \\
\text { Temperature and humidity index (THI) }\end{array}$ & $71,12 \pm 0,55$ & $70,35 \pm 0,54$ & $86,47 \pm 0,34$ & $77,89 \pm 0,41$ \\
\hline $\begin{array}{l}\text { Temperatura do globo negro }(\mathrm{TGN}),{ }^{\circ} \mathrm{C} \\
\text { Black globe temperature }(B G T),{ }^{o} \mathrm{C}\end{array}$ & $21,95 \pm 0,40$ & - & $36,08 \pm 0,24$ & - \\
\hline $\begin{array}{l}\text { Temperatura do Botsball (TB), }{ }^{\circ} \mathrm{C} \\
\text { Botsball temperature }(B T),{ }^{o} C\end{array}$ & $19,67 \pm 0,27$ & - & $32,18 \pm 0,21$ & \\
\hline
\end{tabular}

O aumento da freqüência respiratória e temperatura retal está de acordo com os resultados obtidos nos trabalhos de BIANCA e KUNZ (1978), SERGENT et al. (1985), KAUSHISH et al. (1987), GAY ÃO et al. (1991), BACCARI et al. (1996a) e BACCARI et al. (1997). O aumento no volumeminuto respiratório e na termólise-evaporativa respiratória dos animais sob estresse estão de acordo com aqueles encontrados por BACCARI et al. (1997). Entretanto, esses autores, que trabalharam com cabras Alpinas não-lactantes em câmara climática, encontraram valores mais baixos nos animais estressados $(18,40 \mathrm{~L} / \mathrm{min}$ e $14,59 \mathrm{kcal} / \mathrm{h}$, respectivamente). A média da taxa de sudorese nas cabras sob estresse está abaixo dos valores reportados por DAS (1995), em caprinos da raça Sirohi em crescimento, e BACCARI et al. (1996a) e BACCARI et al. (1997), em cabras Saanen em lactação e Alpinas não-lactantes, respectivamente, sob estresse em câmara climática, que obtiveram 68,$78 ; 48,1 ; \mathrm{e} 43,97 \mathrm{~g} / \mathrm{m}^{2} / \mathrm{h}$, respectivamente. Discrepâncias dos resultados citados acima, comparativamente aos obtidos na presente pesquisa, revelaram diferenças entre raças, estado fisiológico dos animais e duração e intensidade do estresse. Raças indianas são mais adaptadas às condições de temperaturas elevadas, possuindo melhor capacidade de perder calor através da sudorese. Animais em crescimento e em lactação possuem taxa metabólica mais elevada e são mais sensíveis ao calor. As cabras submetidas a estresse aumentaram a freqüência respiratória e diminuíram o volume-corrente respiratório, obtendo maior volume-minuto respiratório ou taxa de ventilação. Em condições de estresse térmico, as cabras exibiram taquipinéia, tanto de manhã como à tarde, aumentaram o volume-minuto respiratório, a termólise-evaporativa respiratória e a sudorese, para promover a perda de calor do organismo, na tentativa de manter a temperatura corporal dentro dos limites normais pelos processos evaporativos respiratório e cutâneo e evitar a hipertermia. Ainda assim, o armazenamento de calor da manhã para a tarde conduziu à hipertermia $\left(40,7^{\circ} \mathrm{C}\right)$, a qual, no entanto, foi temporária, pois a temperatura retal estava dentro dos limites normais na manhã seguinte $\left(39,11^{\circ} \mathrm{C}\right)$, revelando que o excesso de calor armazenado no decorrer do dia foi dissipado durante a noite. Pela manhã, freqüência respiratória média de 79,98 mov/min auxiliou os animais estressados a perder calor e manter a temperatura corporal dentro dos limites considerados normais; porém, à tarde, mesmo dobrada a freqüência respiratória (173,81 vs 79,98 mov/min), associada à elevação da taxa de sudorese, estas cabras não conseguiram evitar a hipertermia. Os valores observados para o volume globular revelaram que as cabras estressadas pelo calor apresentaram hemodiluição, causada pelo alto consumo de água $\left(462,41\right.$ vs $\left.218,17 \mathrm{~mL} / \mathrm{kg}^{0,75} / \mathrm{dia}\right)$ nas horas mais quentes do dia. Estes resultados discordam dos obtidos por SERGENT et al. (1985), em caprinos crioulos expostos à radiação solar direta; HASSAN (1989), em caprinos das raças Anglo-Nubiana, Baladi e seus cruzamentos; e OLSSON et al. (1995), em cabras desidratadas prenhes, que revelaram hemoconcentração, devido à desidratação, quando estressadas. Ao contrário, BACCARI et al. (1996a) e BACCARI et al. (1997), estudando cabras Saanen em lactação e 
1636 Rev. bras. zootec.

Tabela 2 - Respostas fisiológicas (médias de quadrados mínimos e coeficientes de variação) de cabras Alpinas em lactação sob condições termoneutras (TN) ou estresse térmico (ST)

Table 2 - Physiological responses (least squares means and coefficients of variation) of lactating Alpine goats under thermoneutral (TN) or heat stress (ST) conditions

\begin{tabular}{|c|c|c|c|c|c|c|}
\hline \multirow[t]{2}{*}{$\begin{array}{l}\text { Variável } \\
\text { Variable }\end{array}$} & \multirow[t]{2}{*}{$\begin{array}{c}\text { Período } \\
\text { Period }\end{array}$} & \multirow[t]{2}{*}{$\begin{array}{c}\text { Tratamento } \\
\text { Treatment }\end{array}$} & \multicolumn{2}{|c|}{$\begin{array}{l}\text { Média de período } \\
\text { Period mean }\end{array}$} & \multicolumn{2}{|c|}{$\mathrm{CV}(\%)$} \\
\hline & & & $\mathrm{TN}$ & ST & A & B \\
\hline & & & & & $\begin{array}{c}\text { Tratamentos } \\
\text { Treatments }\end{array}$ & $\begin{array}{l}\text { Períodos } \\
\text { Periods }\end{array}$ \\
\hline Resp. freq. & $\begin{array}{l}\text { Manhã } \\
\text { Morning }\end{array}$ & $35,92^{b}$ & $79,98^{b}$ & 37,95 & 78,27 & 40,42 \\
\hline Breaths/min & $\begin{array}{l}\text { Tarde } \\
\text { Evening } \\
\text { Média de } \\
\text { Tratamento } \\
\text { Treatment mean }\end{array}$ & $\begin{array}{l}39,23^{\mathrm{a}} \\
37,58^{\mathrm{B}}\end{array}$ & $\begin{array}{l}173,81^{\mathrm{a}} \\
126,90^{\mathrm{A}}\end{array}$ & 106,52 & - & - \\
\hline $\begin{array}{l}\text { Volume corrente } \\
\text { (mL/resp.) }\end{array}$ & $\begin{array}{l}\text { Manhã } \\
\text { Morning }\end{array}$ & $529,36^{\mathrm{a}}$ & $361,48^{a}$ & 445,45 & 28,45 & 17,53 \\
\hline $\begin{array}{l}\text { Tidal volume } \\
\text { ( } m L / \text { resp.) }\end{array}$ & $\begin{array}{l}\text { Tarde } \\
\text { Evening } \\
\text { Média de } \\
\text { Tratamento } \\
\text { Treatment mean }\end{array}$ & $\begin{array}{l}529,75^{\mathrm{b}} \\
529,57^{\mathrm{A}}\end{array}$ & $\begin{array}{l}215,93^{\mathrm{b}} \\
288,71^{\mathrm{B}}\end{array}$ & 372,35 & - & - \\
\hline $\begin{array}{l}\text { Volume respiratório } \\
\text { (L/min) }\end{array}$ & $\begin{array}{l}\text { Manhã } \\
\text { Morning }\end{array}$ & $18,95^{\mathrm{b}}$ & $27,96^{\mathrm{b}}$ & 23,46 & 26,34 & 17,80 \\
\hline $\begin{array}{l}\text { Respiratory volume } \\
(\mathrm{L} / \mathrm{min})\end{array}$ & $\begin{array}{l}\text { Tarde } \\
\text { Evening } \\
\text { Média de } \\
\text { Tratamento } \\
\text { Treatment mean }\end{array}$ & $\begin{array}{l}21,96^{\mathrm{a}} \\
20,42^{\mathrm{B}}\end{array}$ & $\begin{array}{l}33,48^{\mathrm{a}} \\
30,72^{\mathrm{A}}\end{array}$ & 27,72 & - & - \\
\hline $\begin{array}{l}\text { Term. evaporativa } \\
\text { (kcal/h) }\end{array}$ & $\begin{array}{l}\text { Manhã } \\
\text { Morning }\end{array}$ & $7,04^{\mathrm{b}}$ & $17,08^{b}$ & 23,46 & 40,0 & 19,08 \\
\hline $\begin{array}{l}\text { Respiratory } \\
\text { thermolysis } \\
(\text { kcal/h) }\end{array}$ & $\begin{array}{l}\text { Tarde } \\
\text { Evening } \\
\text { Média de } \\
\text { Tratamento } \\
\text { Treatment mean }\end{array}$ & $\begin{array}{l}7,92^{\mathrm{a}} \\
7,48^{\mathrm{B}}\end{array}$ & $\begin{array}{l}22,59^{\mathrm{a}} \\
19,84^{\mathrm{A}}\end{array}$ & 27,72 & - & - \\
\hline $\begin{array}{l}\text { Temperatura } \\
\text { retal }\left({ }^{\circ} \mathrm{C}\right)\end{array}$ & $\begin{array}{l}\text { Manhã } \\
\text { Morning }\end{array}$ & $39,04^{b}$ & $39,17^{b}$ & 39,10 & 1,02 & 0,82 \\
\hline $\begin{array}{l}\text { Rectal temperature } \\
\left({ }^{o} \mathrm{C}\right)\end{array}$ & $\begin{array}{l}\text { Tarde } \\
\text { Evening } \\
\text { Média de } \\
\text { tratamento } \\
\text { Mean of treatment }\end{array}$ & $\begin{array}{l}39,19^{\mathrm{a}} \\
39,11^{\mathrm{B}}\end{array}$ & $\begin{array}{l}40,74^{\mathrm{a}} \\
39,96^{\mathrm{A}}\end{array}$ & 39,97 & - & - \\
\hline
\end{tabular}

A,B Médias de tratamentos seguidas de letras maiúsculas distintas são diferentes $(P<0,05)$.

a,b Médias de períodos ou de períodos dentro de tratamentos, seguidas de letras minúsculas distintas, são diferentes ( $P<0,05)$.

$A, B$ Means of treatments followed by different capital letters differ $(P<.05)$.

a,b Means of period or periods within treatment, followed by different small letters, differ $(P<.05)$.

cabras Alpinas não-lactantes, respectivamente, em câmara climática, não observaram mudança nos valores do volume globular. Esses autores consideram possível hidratação pelas cabras estressadas causada pelo alto consumo de água nas horas de intenso calor.

$\mathrm{Na}$ Tabela 4, verifica-se que, nas cabras estressadas, houve perda de peso, redução no consumo de matéria seca e duplicação do consumo de água.
Os animais estressados consumiram $62,55 \%$ menos feno no período diurno $(8-17 \mathrm{~h})$. Durante à noite (17$8 \mathrm{~h})$, esta diferença caiu para $15,98 \%$, observando-se efeito compensatório parcial na ingestão de alimentos, que não foi suficiente para alcançar o consumo das cabras não-estressadas. Provavelmente, a temperatura ambiente, aliada à elevada umidade relativa do ar, resultando no THI de 77,9 durante a noite, não 
BRASIL et al.

Tabela 3 - Taxa de sudorese e volume globular (médias de quadrados mínimos e coeficiente de variação) de cabras Alpinas em lactação, sob condições termoneutras (TN) ou estresse térmico (ST)

Table 3 - Sweating rate and packed cell volume (least squares means and coefficient of variation) of lactating Alpine goats under thermoneutral (TN) or heat stress (ST) conditions

\begin{tabular}{lccc}
\hline Variável & \multicolumn{2}{c}{$\begin{array}{c}\text { Médias de tratamentos } \\
\text { Means of treatments }\end{array}$} & CV $(\%)$ \\
\cline { 2 - 3 } & $\mathrm{TN}$ & $\mathrm{ST}$ & \\
\hline Taxa de sudorese $\left(\mathrm{g} / \mathrm{m}^{2} / \mathrm{h}\right)$ & $12,17^{\mathrm{B}}$ & $27,45^{\mathrm{A}}$ & 36,97 \\
$\begin{array}{l}\text { Sweating rate }\left(\mathrm{g} / \mathrm{m}^{2} / \mathrm{h}\right) \\
\text { Volume globular }(\%)\end{array}$ & $25,56^{\mathrm{B}}$ & $22,16^{\mathrm{A}}$ & 7,88 \\
Packed cell volume $(\%)$ & & & \\
\hline
\end{tabular}

$A, B$ Médias de tratamentos seguidas por letras maiúsculas distintas são diferentes $(P<0,05)$.

$A, B \quad$ Treatment means followed by different capital letters differ $(P<.05)$.

Tabela 4 - Ingestão de matéria seca, consumo de água e peso (médias de quadrados mínimos e coeficientes de variação) de cabras Alpinas em lactação sob condições termoneutras (TN) e estresse térmico (ST)

Table 4 - Dry matter intake, water consumption and weight (least squares means and coefficients of variation) of lactating Alpine goats under thermoneutral (TN) or heat stress (ST) conditions

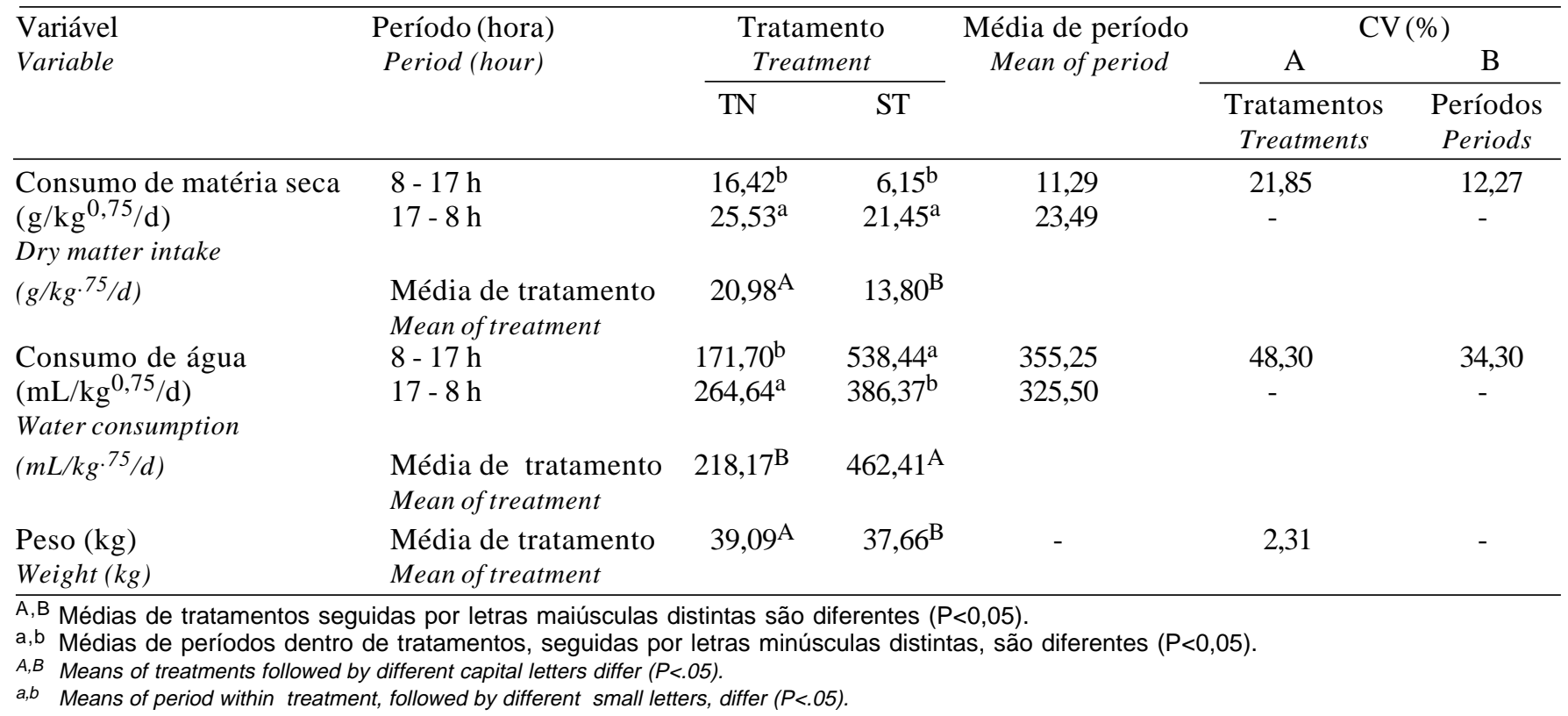

forneceu o alívio suficiente que propiciasse uma resposta compensatória plena em termos de ingestão de alimentos. Esta redução no consumo de alimentos traduziu-se em decréscimo do consumo de nutrientes. Dessa forma, as cabras sob termoneutralidade ingeriram, em média, 0,845 kg/dia de NDT e 0,224 kg/dia de PB e os animais estressados, 0,792 kg/dia de NDT e $0,219 \mathrm{~kg} / \mathrm{dia}$ de PB. Provavelmente, a alta temperatura ambiente e a radiação infravermelha presentes na sala 2 atuaram sobre o centro hipotalâmico do apetite, inibindo o consumo. Redução na ingestão voluntária de alimentos dos animais estressados ob- servados nesta pesquisa corrobora os dados obtidos por HEAD (1989), com vacas holandesas e BACCARI et al. (1996a e 1996b), para cabras Saanen e Saanen-Nativas em lactação de mais baixa produção $(0,90$ e $1,37 \mathrm{~kg} /$ dia $)$ e, portanto, de menor taxa metabólica que as cabras do presente estudo. A variação no consumo de alimentos foi determinada pela ingestão de feno, já que o consumo de concentrado foi total em ambos os tratamentos. Em conseqüência, o teor de fibra da ração consumida pelas cabras estressadas e não-estressadas, foi de 15,77 e $18,45 \%$, respectivamente. 
1638 Rev. bras. zootec.

Observa-se ainda na Tabela 4 que, durante o período experimental, as cabras sob estresse térmico apresentaram redução média de 3,66\% no peso corporal e aumento de $112 \%$ no consumo de água. O maior consumo de água reflete a necessidade de esfriar o organismo por condução e repor a água evaporada pelas vias respiratórias e cutânea. Os dados concordam com os observados por BACCARI et al. (1996a e 1996b), que, trabalhando com cabras Saanen e Saanen-Nativas em lactação, encontraram diferenças significativas no peso corporal e consumo de água dos animais em ambientes quentes. A taquipnéia nas cabras estressadas, observada na presente pesquisa, desviou energia que seria utilizada para os processos produtivos. Redução na ingestão de alimentos diminuiu a energia líquida disponível para mantença e produção de leite, e os animais perderam peso.

$\mathrm{Na}$ Tabela 5, verifica-se que a produção de leite foi menor à tarde, embora esta diferença tenha sido maior sob termoneutralidade. O leite da tarde apresentou maior teor de gordura e sólidos totais e menor de lactose. O teor de proteína bruta foi mais alto pela manhã no leite dos animais estressados, porém mais baixo neste período sob termoneutralidade. A Tabela 5 mostra também que os animais estressados produziram menos leite, com menores teores de gordura, proteína, lactose e sólidos totais.

Na Tabela 6, constata-se que o teor de cinzas foi maior pela manhã e nos animais sob termoneutralidade. Não se verificaram diferenças entre períodos ou tratamentos quanto aos teores de cloretos, cálcio e fósforo.

Resultados semelhantes com relação à produção de leite foram relatados por BARHAT e CHOWDHARY (1978), em raças caprinas indianas, que mostraram produções menores no verão que na estação monçônica $(0,896$ vs $0,763 \mathrm{~kg}$, respectivamente). ESMAIL (1986) observou redução de 36,6\% na produção leiteira de um rebanho de cabras Saanen importado e introduzido numa região tropical e BROWN et al. (1988) verificaram diminuição na produção diária de leite de cabras Alpinas de $3,71 \mathrm{~kg}$ a $20^{\circ} \mathrm{C}$ para $3,49 \mathrm{~kg} \mathrm{a} 34^{\circ} \mathrm{C}$. Ao contrário, B ACCARI et al. (1996a e 1996b) mostraram que cabras mestiças Saanen-Nativas e Saanen submetidas à temperatura

Tabela 5 - Produção e composição química (médias de quadrados mínimos e coeficiente de variação) do leite de cabras Alpinas sob condições termoneutras (TN) ou estresse térmico (ST)

Table 5 - Production and chemical composition (least squares means and coefficients of variation) of milk from Alpine goats under thermoneutral (TN) or heat stress (ST) conditions

\begin{tabular}{|c|c|c|c|c|c|c|}
\hline \multirow{3}{*}{$\begin{array}{l}\text { Variável } \\
\text { Variable }\end{array}$} & \multirow{3}{*}{$\begin{array}{l}\text { Período (hora) } \\
\text { Period (hour) }\end{array}$} & \multirow{2}{*}{\multicolumn{2}{|c|}{$\begin{array}{c}\text { Tratamento } \\
\text { Treatment }\end{array}$}} & \multirow{3}{*}{$\begin{array}{c}\text { Média de período } \\
\text { Mean of period }\end{array}$} & \multicolumn{2}{|c|}{$\mathrm{CV}(\%)$} \\
\hline & & & & & \multirow{2}{*}{$\begin{array}{c}\text { A } \\
\text { Tratamentos } \\
\text { Treatment }\end{array}$} & \multirow{2}{*}{$\begin{array}{c}\text { B } \\
\text { Períodos } \\
\text { Period }\end{array}$} \\
\hline & & $\mathrm{TN}$ & ST & & & \\
\hline Produção de leite (kg) & Manhã (Morning) & $1,35^{\mathrm{a}}$ & $1,26^{\mathrm{a}}$ & 1,31 & 8,32 & 4,80 \\
\hline Milk production $(\mathrm{kg})$ & $\begin{array}{l}\text { Tarde (Evening) } \\
\text { Média de tratamento } \\
\text { Treatment mean }\end{array}$ & $\begin{array}{l}0,69^{\mathrm{b}} \\
1,02^{\mathrm{A}}\end{array}$ & $\begin{array}{l}0,67^{\mathrm{b}} \\
0,96^{\mathrm{B}}\end{array}$ & 0,68 & - & - \\
\hline $\begin{array}{l}\text { Gordura }(\%) \\
\text { Fat }(\%)\end{array}$ & $\begin{array}{l}\text { Manhã (Morning) } \\
\text { Tarde (Evening) } \\
\text { Média de tratamento } \\
\text { Treatment mean }\end{array}$ & $\begin{array}{l}2,77 \\
4,04 \\
3,41^{\mathrm{A}}\end{array}$ & $\begin{array}{l}2,73 \\
3,76 \\
3,25^{\mathrm{B}}\end{array}$ & $\begin{array}{l}2,75^{\mathrm{b}} \\
3,90^{\mathrm{a}}\end{array}$ & $\begin{array}{l}6,72 \\
-\end{array}$ & $\begin{array}{l}7,82 \\
-\end{array}$ \\
\hline $\begin{array}{l}\text { Proteína (\%) } \\
\text { Protein }(\%)\end{array}$ & $\begin{array}{l}\text { Manhã (Morning) } \\
\text { Tarde (Evening) } \\
\text { Média de tratamento } \\
\text { Treatment mean }\end{array}$ & $\begin{array}{l}2,97^{\mathrm{a}} \\
3,05^{\mathrm{b}} \\
3,01^{\mathrm{A}}\end{array}$ & $\begin{array}{l}2,86^{\mathrm{a}} \\
2,78^{\mathrm{b}} \\
2,82^{\mathrm{B}}\end{array}$ & $\begin{array}{l}2,92 \\
2,92\end{array}$ & $\begin{array}{l}6,22 \\
-\end{array}$ & $\begin{array}{l}3,30 \\
-\end{array}$ \\
\hline $\begin{array}{l}\text { Lactose }(\%) \\
\text { Lactose }(\%)\end{array}$ & $\begin{array}{l}\text { Manhã (Morning) } \\
\text { Tarde (Evening) } \\
\text { Média de tratamento } \\
\text { Treatment mean }\end{array}$ & $\begin{array}{l}4,71 \\
4,61 \\
4,66^{\mathrm{A}}\end{array}$ & $\begin{array}{l}4,72 \\
4,53 \\
4,63^{\mathrm{B}}\end{array}$ & $\begin{array}{l}4,72^{\mathrm{a}} \\
4,57^{\mathrm{b}}\end{array}$ & $\begin{array}{l}2,40 \\
-\end{array}$ & $\begin{array}{l}2,23 \\
-\end{array}$ \\
\hline $\begin{array}{l}\text { Sólidos totais }(\%) \\
\text { Total solids }(\%)\end{array}$ & $\begin{array}{l}\text { Manhã (Morning) } \\
\text { Tarde (Evening) } \\
\text { Média de tratamento } \\
\text { Treatment mean }\end{array}$ & $\begin{array}{l}10,77^{\mathrm{b}} \\
12,04^{\mathrm{a}} \\
11,40^{\mathrm{A}}\end{array}$ & $\begin{array}{l}10,41^{\mathrm{b}} \\
11,08^{\mathrm{b}} \\
10,75^{\mathrm{B}}\end{array}$ & $\begin{array}{l}10,46 \\
11,56\end{array}$ & $\begin{array}{l}3,19 \\
-\end{array}$ & $\begin{array}{l}2,00 \\
-\end{array}$ \\
\hline
\end{tabular}

A,B Médias de tratamentos seguidas por letras maiúsculas distintas são diferentes $(P<0,05)$.

a,b Médias de períodos ou de períodos dentro de tratamentos, seguidas por letras minúsculas distintas são diferentes $(P<0,05)$.

$A, B$ Treatment means followed by different capital letters differ $(P<.05)$.

$a, b \quad$ Means of period or of periods within treatment, followed by different small letters, differ $(P<.05)$. 
BRASIL et al.

Tabela 6 - Composição mineral (médias de quadrados mínimos e coeficiente de variação) do leite de cabras Alpinas sob condições termoneutras (TN) ou estresse térmico (ST)

Table 6 - Mineral composition (least squares means and coefficients of variation) of milk from Alpine goats under thermoneutral (TN) or heat stress (ST) conditions

\begin{tabular}{|c|c|c|c|c|c|c|}
\hline \multirow{3}{*}{$\begin{array}{l}\text { Variável } \\
\text { Variable }\end{array}$} & \multirow{3}{*}{$\begin{array}{l}\text { Período } \\
\text { Period }\end{array}$} & \multirow{2}{*}{\multicolumn{2}{|c|}{$\begin{array}{c}\text { Tratamento } \\
\text { Treatment }\end{array}$}} & \multirow{3}{*}{$\begin{array}{l}\text { Média de período } \\
\text { Mean of period }\end{array}$} & \multicolumn{2}{|c|}{$\mathrm{CV}(\%)$} \\
\hline & & & & & \multirow{2}{*}{$\begin{array}{c}\text { A } \\
\text { Tratamentos } \\
\text { Treatments }\end{array}$} & \multirow{2}{*}{$\begin{array}{c}\text { B } \\
\text { Períodos } \\
\text { Periods }\end{array}$} \\
\hline & & $\mathrm{TN}$ & ST & & & \\
\hline \multirow{5}{*}{$\begin{array}{l}\text { Cinzas }(\mathrm{g} / 100 \mathrm{~g}) \\
\text { Ashes }(\mathrm{g} / 100 \mathrm{~g})\end{array}$} & Manhã & 0,75 & 0,74 & $0,75^{\mathrm{a}}$ & 5,24 & 4,21 \\
\hline & Morning & & & & & \\
\hline & Tarde & 0,75 & 0,70 & $0,73^{\mathrm{b}}$ & - & - \\
\hline & Evening & & & & & \\
\hline & $\begin{array}{l}\text { Média de tratamento } \\
\text { Mean of treatment }\end{array}$ & $0,75^{\mathrm{A}}$ & $0,72^{\mathrm{B}}$ & & & \\
\hline \multirow{5}{*}{$\begin{array}{l}\text { Cloretos }(\mathrm{mg} / \mathrm{dL}) \\
\text { Chlorides }(m g / d L)\end{array}$} & Manhã & 216,3 & 214,4 & 215,3 & 6,61 & 2,44 \\
\hline & Morning & & & & & \\
\hline & Tarde & 216,2 & 217,7 & 216,9 & - & - \\
\hline & Evening & & & & & \\
\hline & $\begin{array}{l}\text { Média de tratamento } \\
\text { Mean of treatment }\end{array}$ & 216,2 & 216,1 & & & \\
\hline \multirow{5}{*}{$\begin{array}{l}\text { Cálcio }(\mathrm{mg} / \mathrm{dL}) \\
\text { Calcium }(m g / d L)\end{array}$} & Manhã & 92,63 & 93,59 & 93,11 & 11,86 & 10,01 \\
\hline & Morning & & & & & \\
\hline & Tarde & 90,46 & 87,60 & 89,03 & - & - \\
\hline & Evening & & & & & \\
\hline & $\begin{array}{l}\text { Média de tratamento } \\
\text { Mean of treatment }\end{array}$ & 91,54 & 90,59 & & & \\
\hline \multirow{5}{*}{$\begin{array}{l}\text { Fósforo (mg/dL) } \\
\text { Phosphorus }(m g / d L)\end{array}$} & Manhã & 93,33 & 93,38 & 93,36 & 8,51 & 6,30 \\
\hline & Morning & & & & & \\
\hline & Tarde & 93,11 & 84,45 & 88,92 & - & - \\
\hline & Evening & & & & & \\
\hline & $\begin{array}{l}\text { Média de tratamento } \\
\text { Mean of treatment }\end{array}$ & 93,22 & 88,92 & & & \\
\hline $\begin{array}{l}\text { A,B Médias de tratamer } \\
a, b \text { Médias de períodos }\end{array}$ & uidas de letras maiús & inta & entes & $\begin{array}{l}5,05) \text {. } \\
5) .\end{array}$ & & \\
\hline$A, B$ Means of treatment fol & ed by alstinct capital letters alt & & & & & \\
\hline$a, b$ Means of period followe & & & & & & \\
\hline
\end{tabular}

de 38,4 e $32,5^{\circ} \mathrm{C}$ em câmara climática, respectivamente, mantiveram produção de leite semelhante à de suas companheiras em condições de conforto térmico ( 1,37 vs 1,34 e 0,92 vs $0,87 \mathrm{~kg} / \mathrm{dia})$. Estes animais eram de baixa produção e menor taxa metabólica, portanto mais tolerantes ao estresse térmico, porém perderam peso, levando a supor que mobilizaram tecido corporal para manter a produção de leite. A produção de leite da manhã foi sempre superior à da tarde, em ambos os tratamentos, apesar de as produções terem sido menores no grupo estressado. Provavelmente, o efeito mais pronunciado tenha sido o tempo de intervalo entre as ordenhas, que foi de $8 \mathrm{~h}$ para a tarde e de $16 \mathrm{~h}$ para a manhã do dia seguinte. A maior produção pela manhã está de acordo com ECKLES et al. (1951), SHIPE (1969) e DEVENDRA (1981).

$\mathrm{O}$ efeito do estresse térmico, embora de menor expressão, pode explicar parte da variação leiteira entre os períodos observada nesta pesquisa. Nas cabras estressadas, o armazenamento de calor da manhã para a tarde, devido ao aumento da temperatura ambiente efetiva, levou à hipertermia, resultando em menor produção de leite à tarde. Contudo, o excesso de calor armazenado durante o dia, em parte, era dissipado à noite; além disso, os animais consumiram $71 \%$ a mais de alimento durante o dia. De manhã, quando a temperatura da sala 2 foi mais amena e a perda de calor pela freqüência respiratória permitiu aos animais manterem a temperatura corporal dentro dos limites normais, ocorreu redução na produção de leite. Como os principais componentes do leite estão intimamente relacionados com a produção e o tempo de intervalo de uma ordenha a outra, a tendência é que estes diminuam pela manhã e aumentem à tarde. Isto foi observado no presente trabalho 
para o teores de gordura, sólidos totais, em ambos os tratamentos, e para a proteína no leite, em cabras sob termoneutralidade. Para os teores de lactose, embora os valores obtidos tenham sido maiores pela manhã em ambos os tratamentos, estas diferenças não foram significativas. Os resultados encontrados para cloretos e cinzas discordam dos relatados por DIAS et al. (1995), que observaram maior concentração destes constituintes no leite da tarde. Quanto à lactose, os presentes resultados concordam com os achados de TANEZINI et al. (1995), que não verificaram diferença estatística entre manhã e tarde.

No presente trabalho, os animais sob estresse térmico apresentaram redução de 5,4\% na produção de leite, próxima à relatada por BROWN et al. (1988), que observaram declínio de 6\% em cabras Alpinas. Estes animais são provavelmente mais sensíveis às condições ambientes, em virtude de sua mais elevada produção de leite estar associada à maior produção interna de calor. Diferenças mais acentuadas foram observadas por ESMAIL (1986) em um rebanho Saanen importado, cuja produção de leite declinou de 2,84 a $1,80 \mathrm{~kg} / \mathrm{dia}$, quando a temperatura local da região estava $12^{\circ} \mathrm{C}$ acima da região de origem.

Em relação às análises químicas (Tabelas 6 e 7), verifica-se que os resultados encontrados nesta pesquisa para porcentagem de gordura, proteína e sólidos totais corroboram aqueles relatados por BROWN et al. (1988), com cabras em lactação, e HEAD (1989) e KUME et al. (1990), com vacas holandesas, mas discordam dos observados por BONASSI et al. (1996b e 1997), com cabras, que não encontraram correlação destes componentes com as condições climáticas. Estes últimos, no entanto, relataram que provável confundimento entre temperatura e estádio de lactação tenha influenciado os resultados; além disso, trabalharam com os animais dentro da zona de termoneutralidade.

Menor ingestão de fibra por parte das cabras estressadas observada na presente pesquisa, provavelmente, deprimiu o teor de gordura do leite, o que está de acordo com os trabalhos conduzidos por STANLEY e OLBRICH (1975), que verificaram diferenças significativas entre o nível de fibra da dieta e a porcentagem de gordura no leite de vacas holandesas. TSAI et al. (1967) relataram que baixo nível de fibra na ração reduz o estresse pelo calor e aumenta a produção de leite de vacas mantidas sob altas temperaturas. Contudo, de acordo com
SUDWEEKS (1981), o teor de fibra na ração é importante e necessário para manter balanço adequado da fermentação ruminal e prevenir queda no teor de gordura do leite e diminuição no $\mathrm{pH}$ ruminal. A menor ingestão de alimentos pelas cabras estressadas e não-estressadas traduziu-se em decréscimo do consumo de proteína bruta na ração, cuja estimativa foi de $0,219 \mathrm{e} 0,224 \mathrm{~kg} /$ dia, respectivamente.

Os dados de lactose discordam dos observados por BONASSI et al. (1996a), que não verificaram diferenças entre inverno e verão. Entretanto, esses autores relataram que a variação não foi uniforme durante os anos analisados. Por outro lado, TANEZINI et al. (1995) encontraram valores mais elevados no verão, nos meses chuvosos. No presente trabalho, em relação às cinzas, observou-se menor valor no leite dos animais sob estresse térmico. BONASSI et al. (1997) não observaram diferença estatística entre verão e inverno deste componente, enquanto JENNESS (1980) encontrou valores superiores para cinzas no inverno. Para cálcio e fósforo, não se observou diferença entre os tratamentos aplicados neste experimento, o que discorda de KUME et al. (1990), que afirmam terem estes componentes ligeira tendência a diminuir no verão. Também HEAD (1989) observou declínio destes minerais no leite de vacas estressadas. Entretanto, DIAS et al. (1995) relataram valores mais elevados no verão, coincidindo com o período das águas. Resultados conflitantes quanto à composição mineral do leite caprino devem-se provavelmente ao efeito indireto dos elementos climáticos sobre a produtividade animal, afetando a quantidade e a qualidade dos pastos nas diferentes estações do ano. No presente trabalho, a queda na produção de leite e concentração de seus componentes nos animais estressados pode ser explicada pela diminuição na ingestão de nutrientes e no desvio de energia para funções não-produtivas.

\section{Conclusões}

As cabras Alpinas com produção média de leite de $2,5 \mathrm{~kg} / \mathrm{dia}$ em ambiente quente, caracterizado por alta temperatura efetiva e radiação solar simulada, sofreram estresse térmico, reduziram a ingestão de alimentos, aumentaram o consumo de água, perderam peso, apresentaram declínio significativo na produção de leite e seus componentes e utilizaram os mecanismos termorreguladores para manter a endotermia. 


\section{Referências Bibliográficas}

ASSOCIATION OF OFFICIAL ANALYTICAL CHEMIST AOAC. 1975. Official methods of analysis. 12.ed. Washington, D.C. 1094p.

BACCARI JR., F., GAYÃO, A.L.B.A., GOTTSCHALK, A.F. et al. 1996a. Metabolic rate and some physiological and production responses of lactating Saanen goats during thermal stress. In: INTERNATIONAL CONGRESS OF BIOMETEOROLOGY, 14, 1996, Ljubjlana. Proceedings... Ljubjlana: International Society of Biometeorology, 1996a. p.119.

BACCARI JR., F., GONÇALVES, H.C., MUNIZ, L.M.R. et al.1996b. Milk production serum concentrations of thyroxine and some physiological responses of Saanen - Native goats during thermal stress. Rev. Vet. Zoot., 8:9-14.

BACCARI JR., BRASIL, L.H.A., TEODORO, S.M. 1997. Thermoregulatory responses of Alpine goats during thermal stress. In: LIVESTOCK ENVIRONMENT, 5, 1997, Minneapolis. Proceedings... Minneapolis : Amer. Soc. Agric. Engrs., p.789-94.

BARHAT, N.K., CHOWDHARY, M.S. 1978. Factors affecting some production traits in Rajasthani goats. Ind. J. Dairy Sci., $31: 185-88$

BERMAN, A. 1957. Influence of some factors on the relative evaporative rate from the skin of cattle. Nature, 179(4572):1256.

BIANCA, W., KUNZ, P. 1978. Physiological reactions of three breeds of goats to cold, heat and high altitude. Livest. Prod. Sci., 5:57-9.

BONASSI, I.A., KROLL, L.B., ROÇA,R. Avaliação de cloretos e lactose em leite de cabra. In: CONGRESSO NACIONAL DE LATICÍNIOS, 14, 1996, Juiz de Fora. Anais...Juiz de Fora: EPAMIG, 1996a, p.32-41.

BONASSI, I.A., KROLL, L.B., VIEITES, R.L. 1996b. Composição protéica do leite de cabra. Ciênc. Tecnol. Aliment. 16(3):218-22.

BONASSI, I.A., MARTINS, D., ROÇA, R. de O. 1997. Composição química e propriedades físico-químicas do leite de cabra. Ciênc. Tecnol. Aliment., 17(1):57-63.

BOTSFORD, J.H. 1971. A wet globe termometer for environmental heat measurement. Am. Ind. Hyg. Assoc. J., 32:1-1.

BROWN, D.L., MORRISON, S.R., BRADFORD, G.E. 1988 Effects of ambient temperature on milk production of Nubian an Alpine goats. J. Dairy Sci., 71:2486-90.

DAS, S.K. 1995. A note on cutaneous evaporative loss in Sirohi goats. Ind. Vet. J., 72:771-2.

DEVENDRA, C. 1981. Potential of sheep and goat in less developed countries. J. Anim. Sci., 51(2):461-73.

DIAS, J. M., TANEZINI, C.A., PONTES, I.S. 1995. Características minerais do leite caprino "in natura" da bacia leiteira de Gôiania. Ciênc. Tecnol. Aliment., 15(1):24-28.

ECKLES, C. H., COMBS, W.B., MACY, H. 1951. Milk and milk products. New York: McGraw-Hill. 454p.

ERIKSSON, L., HYDBING, E., TUOMISTO, L. et al. 1994. Intraruminal fluid administration to goats: effects of handling and fluid temperature. Acta Vet. Scand., 35:289-98.

ESMAIL, S.H.M. 1986. Acclimatization of improved Saanen goats in North Yemen. World Rev. Anim. Prod., 22(1):80-82.

GAYÃO, A.L.B.A., BACCARI JR., F. MASSONE, F. et al. Respostas termorreguladoras de cabras mestiças SaanenNativa submetidas a stress térmico de curta duração. In: REUNIÃO ANUAL DA SOCIEDADE BRASILEIRA ZOOTECNIA, 26, 1991, Porto Alegre. Anais... Porto Alegre: SBZ, 1991. p.492.

HAHN, G.L.1985. Management and housing of animals in hot environment. In: YOUSEF, M.K. (Ed.) Stress of phisiology in livestock. Boca Raton: CRC Press, 2. p.151-165.

ASSAN, G.E.A. 1989. Physiological responses of Anglo-Nubian and Baladi goats and their crossbreds to water deprivation uder subtropical conditions. Livest. Prod. Sci., 22 (2-3) : 295-304.
1641

HEAD, H.H. The strategic use of the physiological potential of the dairy cow. In: SIMPÓSIO: "LEITE NOS TRÓPICOS NOVAS ESTRATÉGIAS DE PRODUÇÃO”, 1989, Botucatu. Anais... Botucatu, UNESP, 1989. p.38-89.

HOWARD ENGINEERING COMPANY. 1981. Here's the Botsball thermometer, a simple way to measure heat. Bethlehem, PA (Instructions).

INSTITUTO ADOLFO LUTZ. 1985. Métodos químicos e físicos para análise de alimentos: normas analíticas. 3.ed. São Paulo. 533p.

JENNESS, R. 1980. Composition and characteristics of goat milk: Review 1968-1979. J.Dairy Sci., 63(10):1605-1613.

JUARÉZ, M. 1986. Physico-chemical characteristics of goat"s milk as distinct from those of cow's milk. Bull. Intern. Dairy Fed., 202:54-67.

KAUSHISH, S.K., GEORGIIE, G.C., SENGUPTA, B.P. 1987. Effect of heat and water restriction on physiological responses of Beetal and Black Bengal goats. Ind. J. Anim. Sci., 57(5):461-65.

KELLY, C.F., BOND, T.E. 1971. Bioclimatic factors and their measurement. In: NATIONAL ACADEMY OF SCIENCES. A guide to environmental research on animals. p.7-92.

KUME, S., TAKAHASHI, S., KURIHARA, M. et al. 1990. The effects of heat stress on milk yield, milk composition, and major mineral cows during early lactation. J. Zootech. Jpn. Sci., 61(7):627-32.

LU, C.D.1989. Effects of heat stress on goat production. Small Rum. Res., 2:151- 62.

MALAVOLTA, E., VITTI, G.C., OLIVEIRA, S.A. 1989. Avaliação do estado nutricional das plantas. Princípios $e$ aplicações. Piracicaba: Associação para Pesquisa da Potassa e do Fosfato. 201p.

McDOWELL, R.E., MOODY,E.G., VAN SOEST, P.J. et al.1969. Effects of heat stress on energy and utilization of lactating cows. J.Dairy Sci., 52:188

McDOWELL, R.E. 1975. Bases biológicas de la Producción animal en zonas tropicales. In: Factores que influem en la producción ganadera de los climas cálidos. Zaragosa. Acribia. $691 \mathrm{p}$.

OLSSON, HERMELIN-JOSATER, M, HILALI-HOSSAINE, J. et al. 1995. Heat stress causes excessive drinking in fed and food deprived pregnant goats. Comp. Biochem. Physiol., 10(4):309-17.

SCHLEGER, A.V., TURNER, H.G. 1965. Ewating rate of cattle in the field and their reaction to diurnal seasonal changes. Aust. J. Agric. Res., 16:92-106.

SERGENT, D., BERBIGIER, P., KANN, G. et al. 1985. The effect of sudden solar exposure on thermophysiological parameters and on plasma prolactin and cortisol concentrations in male creole goats. Reprod. Nutr. Dev., 25(4A):629-40.

SHIPE, W.F. 1969. The freezing point of milk. A review. J. Dairy Sci., 42(11):1745-62.

STATISTICAL ANALYSIS SYSTEM. 1985. 6.ed. USA, Cary, NC: SAS. Institute Inc. 429p.

STANLEY, R.W., OLBRICH, S.E. 1975. Effect of roughage level and ambient temperature on milk production, milk composition and ruminal volatile fatty acids. Trop. Agric., 52(3):213-21

SUDWEEKS, E.M., ELY, L.O., MERTENS, D.R. et al. 1981. Assessing minimum amounts and forms of roughages in ruminant diets: Roughage value index sistem. J. Anim. Sci. 53:1404-11.

TANEZINI, C.A., D'ALESSANDRO, W.T., OLIVEIRA, A.B.C. et al. 1995. Variação de lactose no leite cru do município de Goiânia. Ciênc. Tecnol. Aliment., 15(2):162-65.

TSAI, Y.C., CASTILLO, L.S., HARDISON, W.A. 1967. Effect of dietary fiber level on lacting dairy cows in the humid tropics. J. Dairy Sci., 50(7):1126-1129.

Recebido em: 24/05/99

Aceito em: 10/05/00 